Original Research Paper

\title{
Effect of Nano Silica on the Compressive Strength of Harden Cement Paste at Different Stages of Hydration
}

\author{
Justin Montgomery, Taher M. Abu-Lebdeh, Sameer A. Hamoush and Miguel Picornell \\ Department of Civil, Architectural and Environmental Engineering, \\ North Carolina A\&T State University, Greensboro, NC, USA
}

Article history

Received: 15-02-2016

Revised: $17-02-2016$

Accepted: 20-02-2016

Corresponding Author:

Taher Abu-Lebdeh

Department of Civil,

Architectural and Environmental

Engineering, North Carolina A\&T

State University, Greensboro, NC, USA

Email: taher@ncat.edu

\begin{abstract}
This study investigated the compressive strength of hardened cement paste and the formation of Calcium Silicate Hydrate (C-S-H) with the addition of nano silica $\left(\mathrm{SiO}_{2}\right)$. Compressive strength testing was performed using MTS and Forney testing machines to determine stress-strain curves and compressive strength of the materials. The hydration process and formation of C-S-H and Calcium Hydroxide $(\mathrm{CH})$ was examined using Scanning Electron Microscopy (SEM) and Fourier Transform Infrared Spectroscopy (FTIR). This study also incorporates the use of vacuum curing, in comparison to that of the traditional water curing method. Results indicate an increase in compressive strength using 1, 3 and 5\% of nano silica to cement replacement by volume in comparison to the control mix (without nano silica). The optimum cement replacement to yield maximum strength was of the $1 \%$ nano silica content. The formation of $\mathrm{C}$ $\mathrm{S}-\mathrm{H}$ increases significantly during the early testing days which correspond with the drastic increase in compressive strength. The hydration process continues to increase throughout the 56 day trails at a moderate rate. The traditional water curing method proves to be more efficient and beneficial than of the vacuum curing method. However, vacuum cured results showed only about a 5\% reduction in compressive strength after 56 day tests in comparison to the water curing method.
\end{abstract}

Keywords: Nano Silica, Compressive Strength, Hydration of Cement Paste, FTIR, SEM

\section{Introduction}

A series of chemical reactions takes place during the hydration process of cement paste. Once water is added to the cement, the tricalcium aluminate reacts with the gypsum to produce ettringite and heat. Next, the tricalcium silicate is hydrated to produce the C-S-H, lime and heat. Once the gypsum is gone, the ettringite becomes unstable and begins to react with the remaining tricalcium aluminate to form monosulfate aluminate hydrate crystals (Winter, 2012). During a sulfate deficient solution the monosulfate crystals become unstable. The crystals then resort back into ettringite during the presence of sulfates. The increase in the crystal size is what causes the cement cracking when subjected to sulfate attack. The belite hydrates to form $\mathrm{C}-\mathrm{S}-\mathrm{H}$ and heat. The C-S-H during this phase generates strength within the cement paste. This process has a very slow rate; however, this compound produces the long- term strength of cement concrete. The ferrite goes through two progressive reactions with the gypsum. The first reaction is when the ettringite reacts with the water and gypsum to form ettringite, lime and alumina hydroxides. The second reaction occurs when the ferrite further reacts with the ettringite that was formed during the first reaction in order to produce garnets.

Hydration kinetics has been modeled by several researchers to better understand the reactions and changes Portland cement undergoes during the hydration process. Lin and Meyer (2009) developed a hydration kinetic model for Portland cement based on the thermodynamics of multiphase porous media. Their model considered the effects of cement fineness, chemical composition, water-cement ratio, pressure and curing temperature, to analyze the ultimate degree of hydration and develop a corresponding formula. They concluded that their proposed model adequately demonstrates the different experimental results for 
cement hydration at high pressures and elevated temperatures. Trapote-Barreira (2015) conducted a research dissertation on the dissolution kinetics of calcium silicate hydrate gel and durability of mortar. Examinations were carried out using SEM and Electron Microprobe Analyzer (EPMA). Zaki and Ragab (2009) conducted testing using $0,0.5,0.7$ and $1 \%$ of nano silica in concrete along with $20 \%$ of silica fume in all mixes. They concluded the optimum amount of nano silica was $0.5 \%$ by weight of cementitious material. Gopinath et al. (2012) investigated the effects of nano silica in normal strength concrete using 1.5 and $3 \%$ of nano silica to cement replacement by weight; compared to concrete without nano silica. Their findings portrayed varying results with greater earlier 3 day strength results with $3 \%$ of nano silica and higher 28 days results with $1.5 \%$ of nano silica. Salkhordeh et al. (2011) investigated the effects of recycled concrete as an aggregate and nano silica as cement replacement in Self-Consolidating Concrete (SCC) for 28 day compressive strength. With different percentages of recycled concrete aggregates ranging from 0 to 100 in $20 \%$ intervals and nano silica replacing $10 \%$ of cement weight; they found that adding nano silica to all samples lead to an increase in compressive strength.

Elkady et al. (2013) thorough experimental investigation the reasons for the inconsistencies in the workability and compressive strength of nano silica concrete. The research investigated how agglomeration can affect the compressive strength and workability of normal strength concrete due to different methods of deagglomeration. Results showed that sonication proved to be the most significant de-agglomeration method as it enhanced the gain in compressive strength of concrete by $23 \%$ using only $1 \%$ nano silica to cement substitution. Givi et al. (2010) studied the size effects of $\mathrm{SiO}_{2}$ nano particles on compressive, flexural and tensile strength of binary blended concrete. They specified that the rate of the pozzolanic reaction is related to the surface area existing during the reaction. Thus, it is feasible to add high purity $(99.9 \%)$ nano silica with high Blaine fineness value $\left(60 \mathrm{~m}^{2} / \mathrm{g}\right)$ in order to improve characteristics of cement. Their results showed that nano-particles blended -with concrete increased the compressive, flexural and tensile strength at all curing ages. Belkowita and Armentrout (Belkowitz and Armentrout, 2009) also studied the relationships of using different sizes of nano silica in cement paste. They measured the heat of hydration, concentration of $\mathrm{CH}$ through X-ray diffraction, grain structures through SEM and compressive strength. Their experimental results showed an increase in compressive strength as the C-S-H became more rigid when the nano silica particles decreased in size and their size distribution broadened. Bi et al. (2012) tested nano silica in concrete for compressive strength and durability. The nano silica used was a powder obtained from an extraction process of silica sand. Their results indicated that the combined use of nano silica with silica fume effectively increases the compressive strength and durability of the concrete. Quercia et al. (2012) studied two different types of nano silica in Self-Compacting Concrete (SCC). Both types of nano silica, fumed powder silica and precipitated silica in colloidal suspension have similar particle size distributions; yet, both were produced in different processes. Their results demonstrated that the use of nano silica in SCC can improve the mechanical properties and durability of concrete.

Spectroscopic methods have commonly been used to study the chemistry behind the hydration process of Portland cement. However, the study of cement hydration with the incorporation of nano silica is an uncommon area of study. The main objective of this study is to investigate the effect of nano silica in cement on the hydration process of concrete over the course of 56 days. Fourier Transform Infrared Spectroscopy (FTIR) was used to study the complexity of the hydration chemistry of the Portland cement with the addition of nano silica content. This study investigated the hydration process of Portland cement with increments of nano silica addition by cement replacement, monitored by FTIR and SEM. The results of FTIR spectroscopic signatures were compared to the represented samples examined under SEM. An attempt to correlate the spectroscopic features to the development of concrete strength is also determined. Strength testing was carried out by using Forney Universal Testing and MTS machines for compressive strength and stress-strain. This investigation also studied the effects of water curing in comparison to vacuum curing. Concrete cured in airless environments or vacuum curing, is a new area of interest.

\section{Experimental Program}

\section{Methodology}

This experimental study investigated the strength and hydration of Portland cement with nano silicacompared to cement paste without nanoparticles. Compressive testing was carried out using a Forney and MTS testing machines. FTIR and SEM were used to monitor and portray the chemical transformations of the cement paste. Approximately 250 specimens were prepared to conduct several tests using 4 in. by 8 in. cylinders and 2 in. cubes. Four (4) mix designs were created. The first mix, M1, was the control mix of the cement paste. The next three mixes, M2, M3 and M4, consisted of a 1, 3 and 5\% nano silica by volume of cement, respectively. Nearly half of the specimens created from each mix were cured in water and the other half in vacuum seal. 


\section{Materials}

The materials used in this study were Portland cement Type 1, nano silica and Polycarboxilate polymer based superplasticizer. The nano silica is silicon oxide nanoparticles $\left(\mathrm{SiO}_{2}\right)$ synthetic product of porous and nearly spherical particles. The particle size ranges from $15-20 \mathrm{~nm}$, consisting mainly of pure silica $(>99 \%)$. Table 1 shows the physical properties of the nano silica used herein. The nano silica was obtained from Sky Spring Nanomaterials, Inc., Houston, Texas, while the polycarboxilate was providedby Handy Chemicals Limited, located in Beachwood, Ohio.

The Polycarboxilate, also referred to as Megapol, is a high performance acrylic based polymer. It's specifically developed to improve the workability, strength, flexibility, modulus of elasticity and durability of concrete properties. It is an effective dispersant and High Range Water Reducer (HRWR). The water to cement $(\mathrm{w} / \mathrm{c})$ ratio was 0.27 using superplasticizer.

The cement and nano silica were measured and dry mixed together by hand to reduce the loss of nanoparticles. The polycarboxilate and water were both measured and mixed together. Next, following ASTM Standard C-305, the water with superplasticizer was poured into a rotary mixer bowl (Hobart HL 200, 20 quart mixer). The dry mix of cement and nano silica was then added to the mixer bowl. Once the materials were in the bowl, they were mixed at a low rate (59 agitator rpm) for $30 \mathrm{sec}$. After mixing on low speed, the mixing rate was increased to Level 1 (107 agitator rpm) for one min. After the mixing process concluded, the mixture was carefully poured into cylinder and cube molds. The cylinders and cubes were then rodded, vibrated and leveled before stored away for curing. One cylinder from each batch mixture was weighed and measured to obtain the unit weight after mixing. For this experiment, a total of 120 cubes and 130 cylinders, totaling 250 samples, were manufactured for testing. Half of the manufactured specimens were cured in water while the other half cured in vacuum curing. The cylinders were comprised of plastic molds, 4 inches in diameter and 8 inches in depth, in compliance with ASTM C-470. The cube molds were comprised of brass, exactly 2 inches in size and able to form three cubic specimens within each mold.

Table 1. Physical properties of the nano silica

\begin{tabular}{ll}
\hline Description & Results \\
\hline Particle Size $(\mathrm{nm})$ & $15-20$ \\
Surface Area $\left(\mathrm{m}^{2} / \mathrm{g}\right)$ & 640 \\
Bulk Density $\left(\mathrm{g} / \mathrm{cm}^{3}\right)$ & $0.08-0.10$ \\
Molecular & $\mathrm{SiO}_{2}$ \\
Molecular Weight & 60.08 \\
Porosity $(\mathrm{ml} / \mathrm{g})$ & 0.6 \\
Morphology & Porous and nearly spherical \\
\hline
\end{tabular}

\section{Testing Equipment}

Several testing machines were used throughout this experimental study to obtain required data. The compressive strength data was obtained using the Forney and Material Test System (MTS) machines. The SEM and FTIR were used to analyze the chemistry and microstructure of the testing specimens. The MTS 810 Landmark Servohydraulic Testing system was used to determine compressive strength and stress-strain curves obtained from cube testing. These systems include MTS software, FlexTest controls, MTS servohydraulic technology and a complete selection of accessories. The Forney Universal Testing Machine was used to carry out all cylinders testing, including compression and modulus of elasticity. The Forney machine has a 400 kip load capacity and a load rate of $12,000 \mathrm{lbs} / \mathrm{min}$. The high definition Scanning Electron Microscope (SEM EVO LS) made by ZEISS, was used for microstructure characterization and analysis of the hardened concrete specimens. EVO LS has full environmental capabilities to capture nano scale interactions of samples under various pressures, temperatures and humidity. The Fourier Transform Infrared Spectroscopy- FTIR (Thermo Scientific Nicolet iS10 FT-IR Spectrometer) was used to monitor the changes in C-S-H as the hydration of cement paste take place. This FTIR Spectrometer delivers the highest confidence in the verification and identification of materials. With the use of OMNIC Specta software, the Nicolet iS10 can manage results and provide accurate and valid answers.

\section{Results}

\section{Compressive Strength and Stress-Strain}

The Forney Universal Testing Machine was use to conduct all cylinder compressive strength tests. The results from testing are displayed by column graphs in Fig. 1 and 2. Figure 1 shows the average compressive strengths for all water cured testing cylinders. This figure represents the control, 1 and $3 \%$ of nano silica to cement replacements, against the 3, 7, 14, 28 and 56 day tests. As shown, both the 1 and $3 \%$ nano silica samples performed significantly higher than that of the controlled. To compare the cylinder compressive strengths of the reference curing methods, a separate column graph was created to represent the comparison. Figure 2 displays the average cylinder strength of the $0 \%$ controlled samples that were water and vacuum cured at all testing ages. Results show that the water curing samples produced higher compressive strength at all testing ages than that of the vacuum cured samples.

Stress-strain curves were developed from each hardened cement paste cube tested with the MTS Landmark Servohydraulic testing system. As stated in the experimental procedure, four different percentage 
(control $0,1,3$ and $5 \%$ ) of nano silica were used in the study. For each percentage, six cubes (three for water curing and three for vacuum curing) were cast for each age of testing. The stress-strain curves created from the three cubes were averaged together to obtain a single averaged stress-strain curve.

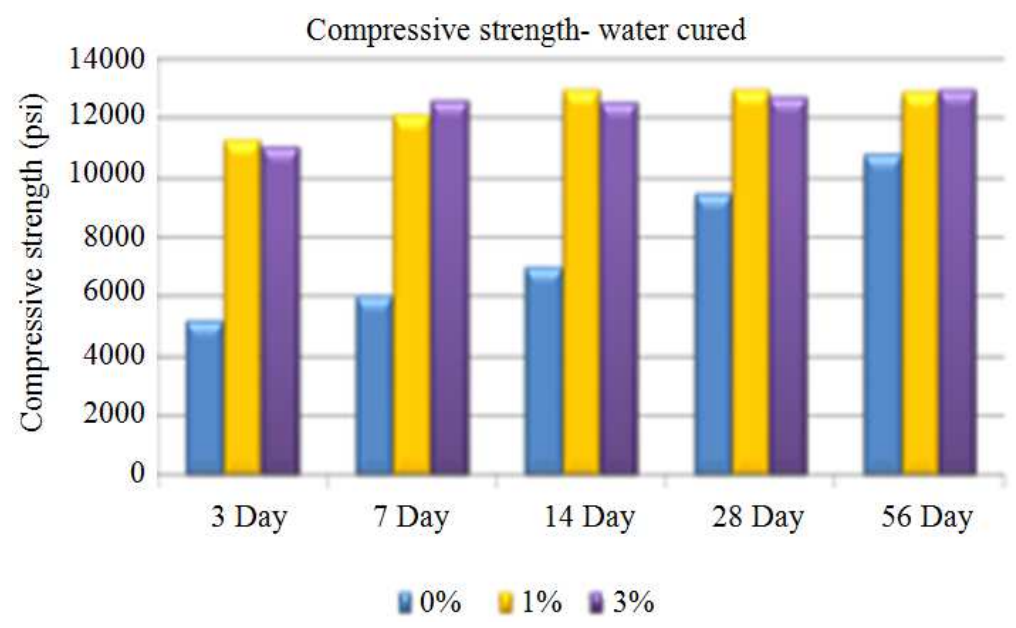

Fig. 1. Compressive strength for all water cured samples

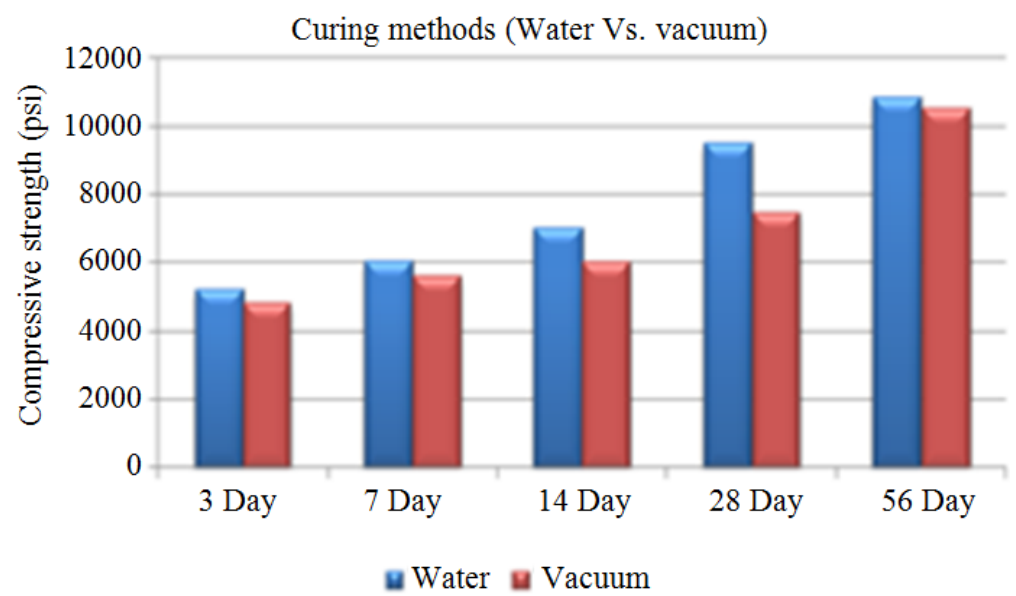

Fig. 2. Compressive strength for different curing method

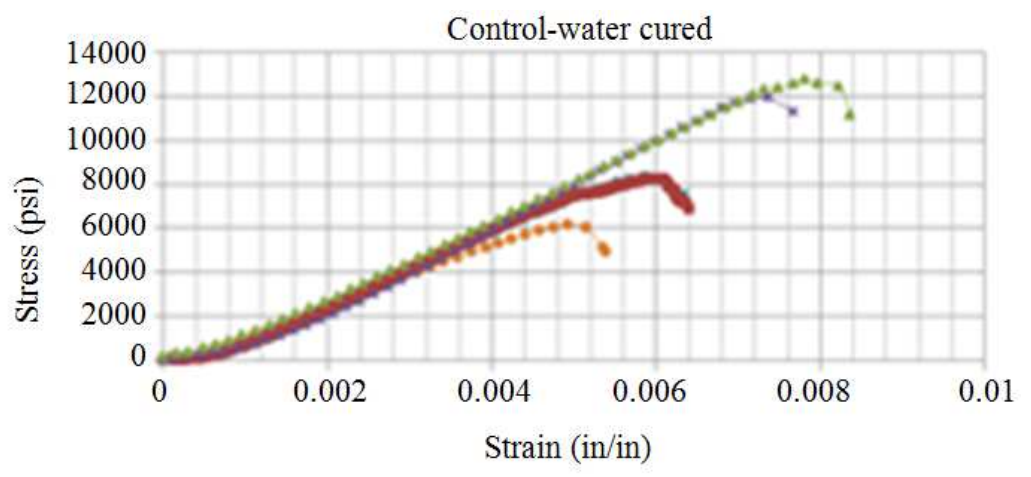

—3 Day - 7 Day —-14 Day — 28 Day — 56 Day

Fig. 3. Stress-strain curves of water cured controlled 
The following stress-strain curves display partial results, while the remaining graphs displaying the different ages and curing methods with the change in nano silica content were developed but not shown here due to page limitations of the manuscript. Figure 3 displays the stress-strain curves for the control samples for all ages and water cured. The graph shows an increase in strength from the 3 day tests, ascending to 56 day tests. Figure 4 displays the stress-strain curves for the control samples for all testing days under vacuum cured. Similar to the results from the control water cured data, the results indicate an increase in strength from the 3 day test, to the 56 day tests. As seen the stress for the 3 day tests were around 6000 psi for the reference samples and over 12,000 psi for the 56 days control samples. Figure 5 displays the $3 \%$ of nano silica to cement replacement for the water cured samples. This figure also shows the stress-strain relationship of the samples for all testing ages. However, with the incorporation of nano silica, the stresses at all testing ages are shown to be much greater than that of the control samples. The stresses for the $3 \%$ nano silica samples range between 12,300 psi for the 3 day results and 14,346 psi for the 56 day results. Figure 6 shows the 3 day stresses for control, 1, 3 and $5 \%$ nano silica replacement for the water cured samples.

\section{Scanning Electron Microscope (SEM)}

The SEM was used to obtain a microscopic images of the tested specimens during all ages of testing. From the images obtained, a further analysis using MatLab was conducted to filter the images using a Gaussian filter and to determine the percentages of chemical products for which that image portrays. The MatLab program was used to filter the SEM images and generate histograms outlying the major constituents of the hydrated cement. Backscatter used in SEM allows grey level identification of the chemical elements. This grey level identification will distinguish the different phases of the hydrated cement products. Four main phases can be identified, which are: Porosity (P), Calcium Hydroxide $(\mathrm{CH})$, Calcium Silicate Hydrate (C-S-H) and Unhydrated Products (UP). Other products such as limestone and other hydrated products were not distinguished. Using the MatLab analysis, it was expected to produce histograms with three or more peaks for all testing samples. The various peaks help distinguish the thresholds which separate the phases from the grey level images. Once the grey level images were filtered, a colored image was generated portraying each phase with a specific color. For this study the following phases were assigned with the specified color: P-Blue, C-S-H-Green, CH-Red and UP-Black. Changes to the thresholds were expected to be seen in the adjusted histogram after running the MatLab script once again. Figure 7 shows the original SEM image of harden cement paste sample containing $1 \%$ nano silica after water curing and tested at 7 day. Figure 8, shows the same sample after filtered using the Gaussian filter. Features from this image are lighter and more distinguished. The following Fig. 9 displays the color phases of the same sample and after filtered. Figure 10 shows the grey level histogram of the sample after filtered. Figure 11 shows the histogram of the same sample with color phases and the percentage of each respected color phase.

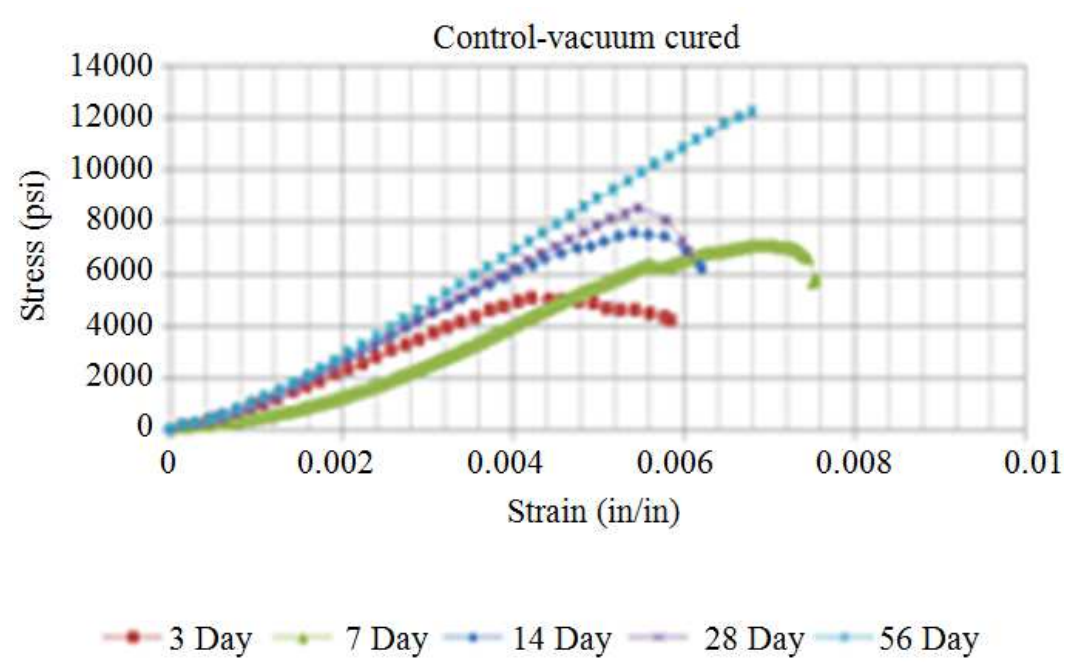

Fig. 4. Stress-strain curves of vacuum cured controlled Specimens at different ages 


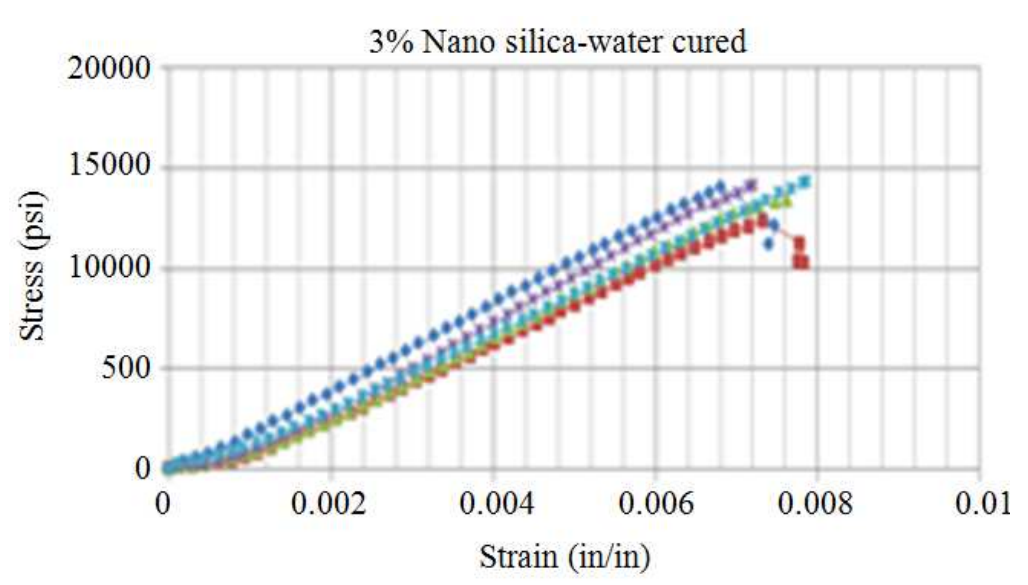

$$
\rightarrow-3 \text { Day } \rightarrow 7 \text { Day } \rightarrow-14 \text { Day } \rightarrow 28 \text { Day } \rightarrow-56 \text { Day }
$$

Fig. 5. Stress-strain curves of $3 \%$ nano silica at different

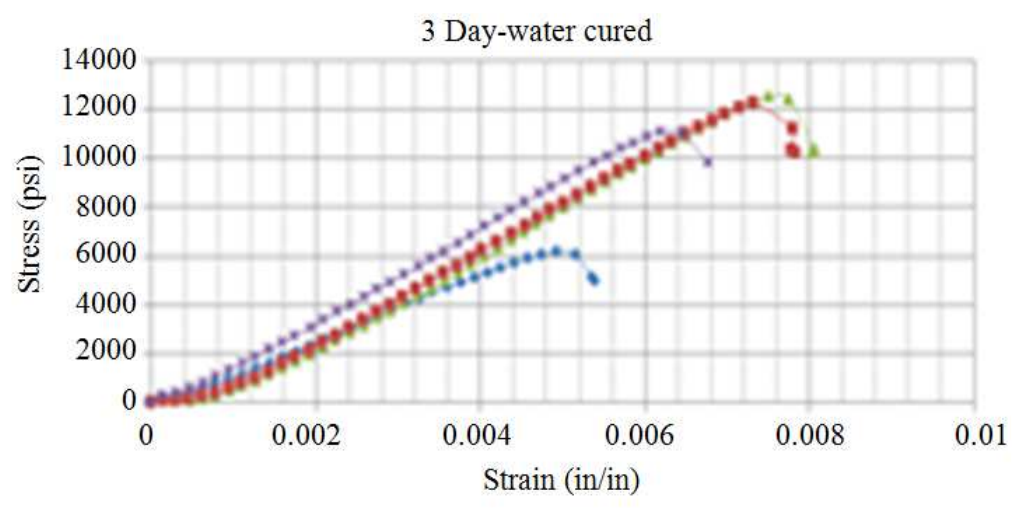

$$
\rightarrow \text { Control } \rightarrow 1 \% \rightarrow-3 \%-5 \%
$$

Fig. 6. Stress-strain curves after 3 days of water curing

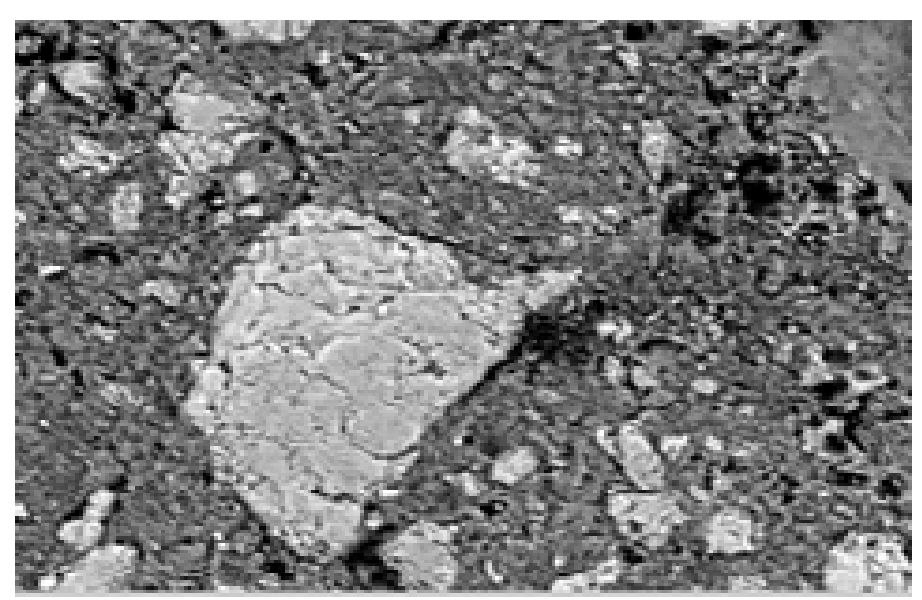

Fig. 7. Grey level of original SEM image 


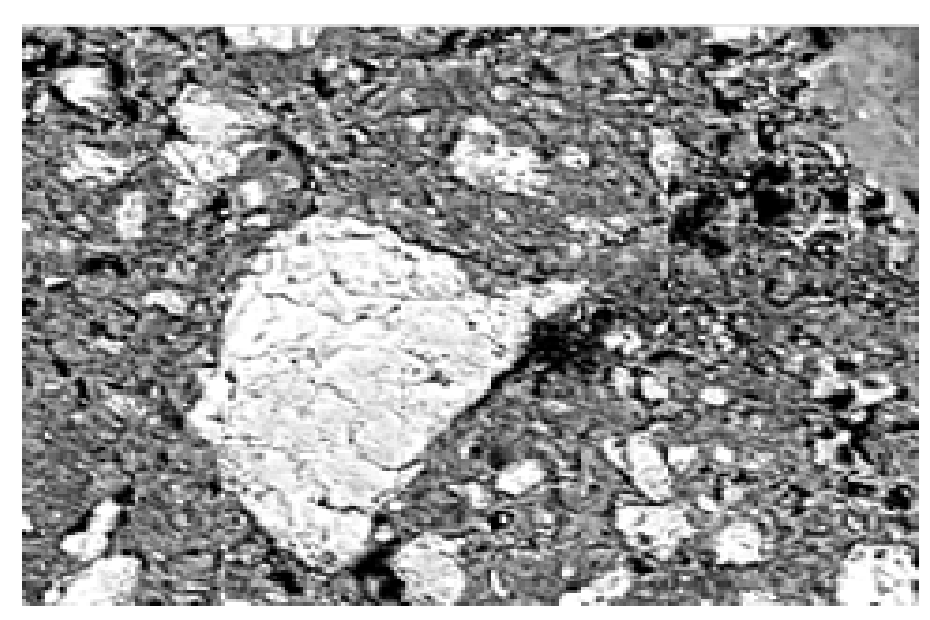

Fig. 8. Grey level SEM image filtered

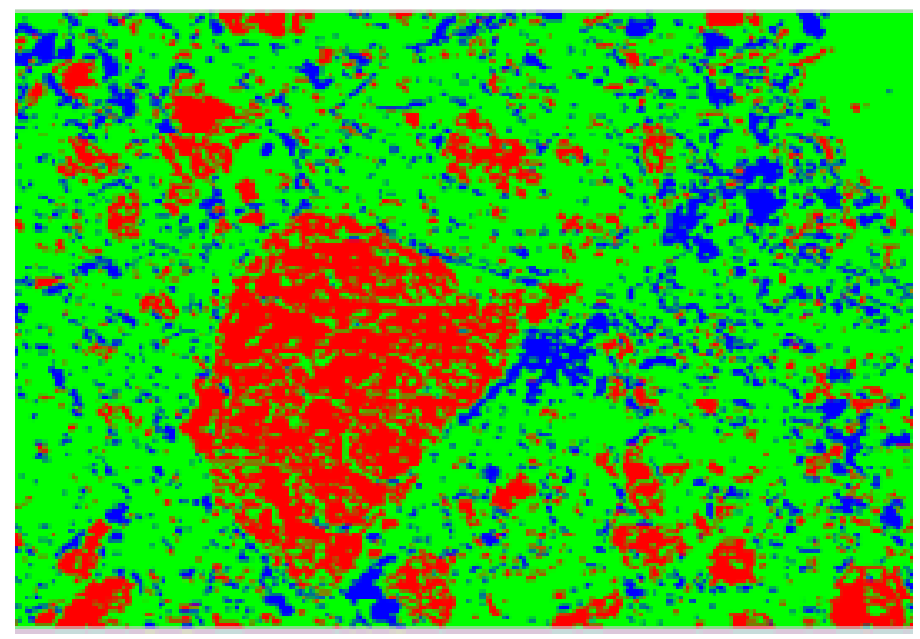

Fig. 9. Grey level SEM image colored phases

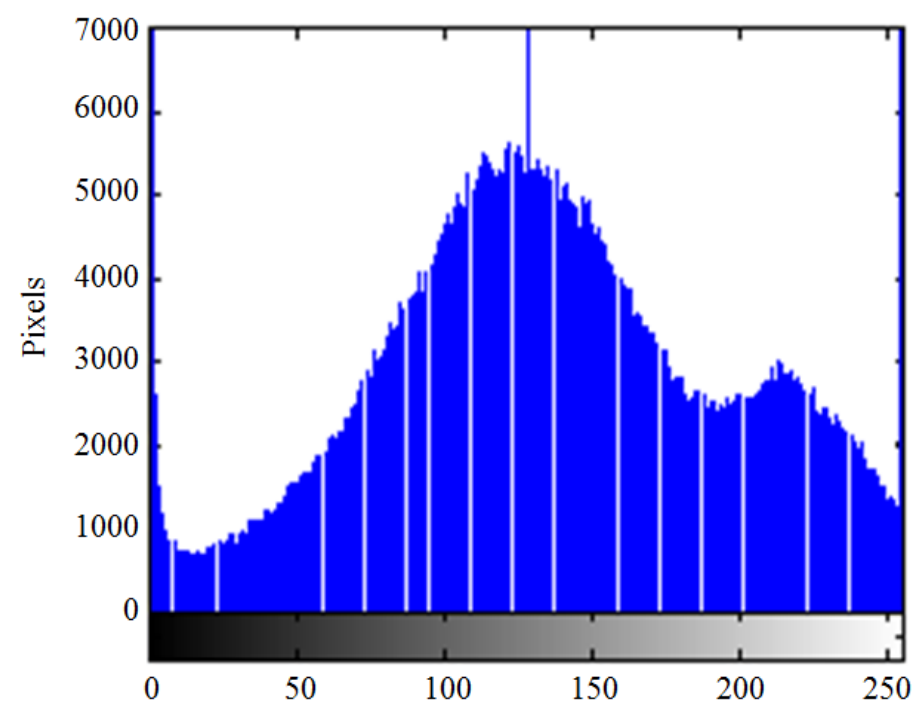

Fig. 10. Grey level histogram 


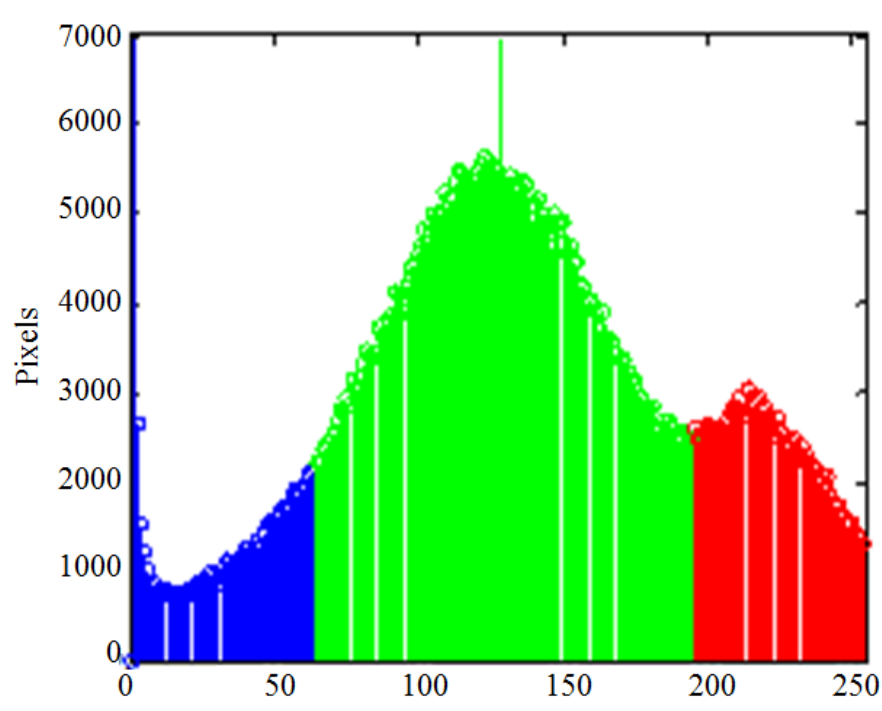

Fig. 11. Grey level histogram colored with phases

Table 2. SEM chemical area results-water cured

\begin{tabular}{|c|c|c|c|c|c|}
\hline \multirow[b]{2}{*}{ Days } & \multirow[b]{2}{*}{ Area } & \multirow{2}{*}{$\begin{array}{l}\text { Control } \\
0 \%\end{array}$} & \multicolumn{3}{|c|}{$\%$ Nano Silica } \\
\hline & & & $1 \%$ & $3 \%$ & $5 \%$ \\
\hline \multirow[t]{3}{*}{3} & $\mathrm{P}$ & 17 & 15 & 11 & 11 \\
\hline & C-S-H & 59 & 65 & 76 & 79 \\
\hline & $\mathrm{CH}$ & 25 & 20 & 13 & 10 \\
\hline \multirow[t]{3}{*}{7} & $\mathrm{P}$ & 11 & 11 & 10 & 4 \\
\hline & C-S-H & 64 & 68 & 80 & 80 \\
\hline & $\mathrm{CH}$ & 25 & 21 & 10 & 15 \\
\hline \multirow[t]{3}{*}{14} & $\mathrm{P}$ & 14 & OUT & 12 & OUT \\
\hline & C-S-H & 66 & OUT & 82 & OUT \\
\hline & $\mathrm{CH}$ & 19 & OUT & 6 & OUT \\
\hline \multirow[t]{3}{*}{28} & $\mathrm{P}$ & 17 & 13 & 8 & 3 \\
\hline & C-S-H & 67 & 77 & 83 & 85 \\
\hline & $\mathrm{CH}$ & 17 & 10 & 10 & 12 \\
\hline \multirow[t]{3}{*}{56} & $\mathrm{P}$ & 10 & 9 & 7 & 3 \\
\hline & C-S-H & 70 & 81 & 85 & 86 \\
\hline & $\mathrm{CH}$ & 20 & 10 & 9 & 12 \\
\hline
\end{tabular}

From the results gathered from the MatLab analysis of all samples, a table was generated to portray the results obtained. Table 2 shows the water cured averages of porosity, calcium silicate hydrate and calcium hydroxide for all testing days under changes in nano silica content. Results from Table 2 show an increase in $\mathrm{C}-\mathrm{S}-\mathrm{H}$ formation from 3 day to 56 day results for the control and all nano silica mixtures. Results show a maximum amount of $\mathrm{C}-\mathrm{S}-\mathrm{H}$ formation in the $5 \%$ nano silica samples than that of the 1 and $3 \%$ nano silica samples. Also, at all testing ages, samples with nano silica out performed or contains more C-S-H content than the control. The 14 day test results performed poorly due to an experimental error, resulting in obscure data results which do not follow the trend of the results obtained. For this reason, several of the 14 day results collected were removed from the analysis and tables thereof. For data that has been removed from the following tables, the cell block will display "OUT". Similar results were obtained for vacuum curing.

\section{Fourier Transform Infrared Spectroscopy (FTIR)}

In this study, the hydration process was monitored for $3,7,14,28$ and 56 days, by acquiring an FTIR spectrum for each sample under water and vacuum curing and for each percentage of nano silica. The process starts with displaying the reference spectrum for the anhydrate dry cement. It was observed two major peaks occur around the wavelength numbers of 877 and $1100 \mathrm{~cm}^{-1}$. From the chemical composition of Portland cement and from past literature for possible assignment for peaks observed on cement spectrum; the peaks can possibly be assigned to the $\mathrm{CaO}$ and the $\mathrm{SiO}_{2}$ for the two peaks respectively. The recorded spectra for the hydrated 3, 7, 28 and 56 day 
water and vacuum cured samples were obtained. There was a large peak in the area of $3400 \mathrm{~cm}^{-1}$, which can be associated with hydrogen bond $(\mathrm{O}-\mathrm{H})$ or capillary water within that region. More than forty (40) curves of the spectra for the 1, 3 and 5\% nano silica spectrums for both curing methods were obtained but not shown. C-S$\mathrm{H}$ is a weak bond structure which appears around 1100 $\mathrm{cm}^{-1}$ and can be associated with the peak in that region. To enhance these effects in the 900 to $1200 \mathrm{~cm}^{-1}$ region, serval difference spectra were created by subtracting the spectrum of the dry cement from the spectrums of the hydrated test samples. By using the dry cement spectrum as a reference, the spectroscopic features within the 900 to $1200 \mathrm{~cm}^{-1}$ region can be seen more clearly and therefore can observe the development of C-S-H within this region. The purpose of this subtraction technique is to remove the bonds of the reference material away from that of the sample material tested. This is performed by determining the difference in absorbance between the two spectra and plotting the difference against the wave number. Figure 12 displays the results from the reference dry cement spectrum subtracted from the control sample spectra for all testing days. Knowing that the formation of C-S-H occurs within the approximate region of 900 to $1100 \mathrm{~cm}^{-1}$, spectra can be zoomed into this area for further analysis. Using the OMNIC software, the area of the peak region associated with $\mathrm{C}-\mathrm{S}-\mathrm{H}$ can be exerted by creating a baseline between the two dips neighboring that region. Once obtaining the possible $\mathrm{C}-\mathrm{S}-\mathrm{H}$ formation from each sample, further analysis was conducted. Table 3 displays the area amounts of C-S-H formation from each sample tested, for all testing days, percentage of nano silica replacement and both water and vacuum cured. The amount of C-S-H found within each sample various amongst the different percentages of nano silica. Results show a drastic increase in C-S-H found from the 28 day to 56 day control samples.

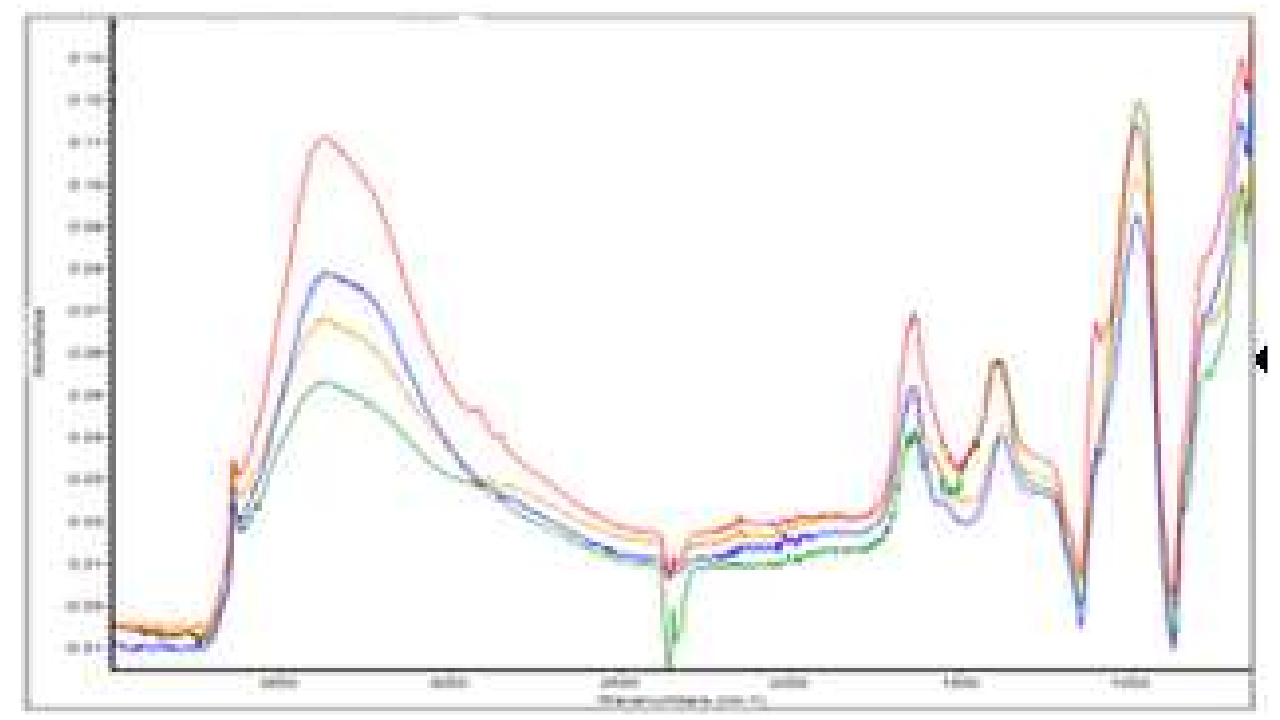

Fig. 12. Difference spectra with subtracted dry cement

Table 3. Change of C-S-H Area with Time

Area and $\Delta$ Area of C-S-H Region

\begin{tabular}{|c|c|c|c|c|c|c|c|c|}
\hline \multirow[b]{2}{*}{ Day } & \multicolumn{4}{|c|}{ Percentage of Nano Silica } & \multicolumn{4}{|c|}{ Change of Area $(\Delta$ Area $) /$ water cured } \\
\hline & $0 \%$ & $1 \%$ & $3 \%$ & $5 \%$ & $0 \%$ & $1 \%$ & $3 \%$ & $5 \%$ \\
\hline 3 & 8.8 & 7.1 & 5.6 & 7.1 & 8.8 & 7.1 & 5.6 & 7.1 \\
\hline 7 & 8.9 & 9.5 & 6.2 & 8.2 & 0.2 & 2.4 & 0.6 & 1.2 \\
\hline 28 & 9.6 & 10.0 & 7.3 & 8.3 & 0.6 & 0.9 & 1.2 & 0.1 \\
\hline \multirow[t]{2}{*}{56} & 13.0 & 12.0 & 9.6 & 10.0 & 3.1 & 1.1 & 2.3 & 2.2 \\
\hline & \multicolumn{4}{|c|}{ Percentage of Nano Silica } & \multicolumn{4}{|c|}{ Change of Area ( $\Delta$ Area) /water cured } \\
\hline Days & $0 \%$ & $1 \%$ & $3 \%$ & $5 \%$ & $0 \%$ & $1 \%$ & $3 \%$ & $5 \%$ \\
\hline 3 & 10 & - & - & - & 7.9 & - & - & - \\
\hline 7 & 10 & 7.6 & 9.1 & 5.7 & 0.3 & 7.6 & 9.1 & 5.7 \\
\hline 28 & 11 & 9.6 & 9.3 & 6.4 & 1.0 & 2.0 & 0.2 & 0.7 \\
\hline 56 & 12 & 12.0 & 11.0 & 7.3 & 0.7 & 2.7 & 2.0 & 0.9 \\
\hline
\end{tabular}


By taking the difference in C-S-H area for each testing day and plotting the change in area with respect to time, the rate of hydration can be determined. Table 3 portrays the changes in C-S-H area for all testing samples and days. Since there was no data obtained prior to the 3 days test results, the C-S-H area was assumed to be the same results gathered from the 3 day tests. The remaining data displays the change in $\mathrm{C}-\mathrm{S}-\mathrm{H}$ area by taking the difference in area from the previous testing day.

\section{Discussion}

\section{Compressive Strength and Stress-Strain}

The control samples depict a continuous increase in strength with age. The 3 day results for the control mix were 5,219 psi and increased to 10,842 psi for the 56 day results. With the addition of nano silica, the compressive strength showed a significant increase in comparison to that of the control concrete at all stages of testing. Water cured samples with the addition of 1 , 3 and $5 \%$ of nano silica to cement replacement, performed approximately double in compressive strength for the 3 day in comparison to the control mix. Nano silica samples of 1 and $3 \%$ displayed the highest stresses for 28 and 56 day tests. The stresses for the $1 \%$ nano silica replacement reached to $14,377 \mathrm{psi}$ and 14,390 psi for the 28 day water and vacuum cured samples, respectively. The $3 \%$ nano silica replacement samples obtained peaked stresses at 14,346 psi and 14,162 psi during the 56 day water and vacuum cured tests, respectively. The $5 \%$ nano silica samples performed poorly in comparison to the 1 and $3 \%$ nano silica concretes in nearly all stages of testing. The compressive strength for the $5 \%$ nano silica samples peaked at 14,182 psi for the 56 day water cured test. However, the $3,7,14$ and 28 day tests for the $5 \%$ nano silica water cured samples, all performed lower than that of the 1 and $3 \%$ nano silica samples. The results indicate the optimum percentage of nano silica to cement replacement is that of the $1 \%$, due to its consistent and higher stresses during majority of all testing ages. Regarding curing method, the two curing methods examined in this study are the commonly used water curing and a new curing method of vacuum sealing. The vacuum cured samples performed weaker in strength in all testing days in comparison to water curing. Yet, the stresses were not too far apart. The water cured control samples ranged from 6,149 psi to $12,793 \mathrm{psi}$, from 3 day to 56 day. The vacuum cured control samples ranged between 5,070 psi to 12,219 psi, from 3 day to 56 day tests. In the cases involving the incorporation of nano silica, results showed decreases in compressive strength with the 3 and $5 \%$ of cement replacement; and approximately the same compressive strength with the $1 \%$ cement replacement amongst testing days. The $1 \%$ nano silica replacement vacuum cured 28 day results recorded nearly identical stresses than that of the 28 day water cured test. The $1 \%$ nano silica samples for 28 day vacuum cured peaked at 14,390 psi; as for the 28 day water cured samples peaked at 14,377 . This comparison shows the optimum nano silica to cement replacement for vacuum curing is $1 \%$. Results also indicate about a 5\% difference in the control mix compressive strength when comparing the 56 day test results of the water and vacuum cured methods. In other comparisons, the strength difference of the vacuum cured samples was nearly identical to that of the water cured method; signifying an adequate curing method for curing concrete.

\section{Scanning Electron Microscope (SEM)}

SEM MatLab analysis results had shown an increase in $\mathrm{C}-\mathrm{S}-\mathrm{H}$ formation over for all mixes throughout the testing days. When comparing the control samples to that of the samples containing nano silica, it was notice the significant increase in $\mathrm{C}-\mathrm{S}-\mathrm{H}$ formation during all testing days with all additions of nano silica. With the increase in C-S-H formation, results signify an increase in strength with the hardened cement samples containing nano silica than the control samples without nano silica. Also, SEM results show a greater increase in C-S-H formation in the samples containing $5 \%$ nano silica to cement replacement in comparison to the 1 and $3 \%$ of nano silica samples. The percentage of $\mathrm{C}-\mathrm{S}-\mathrm{H}$ found in the $5 \%$ nano silica samples was slightly higher than the $3 \%$ nano silica samples through both methods of curing. These results should indicate a greater increase in compressive strength with the 5\% nano silica samples; however, the compressive strength results show the $5 \%$ nano silica samples portraying the lower strength values when compared to the 1 and $3 \%$ nano silica tests. Reasoning behind the dissimilarities could be due to the area of which the SEM images data was gathered and collected to determine the amount of C-S-H or hydrated products. The SEM images only look into one location under $1300 \mathrm{x}$ magnification within a specific sample. Thus, the area examined under the SEM is a small representation of the sample and therefore provides an estimate of the full sample strength. When comparing the water and vacuum curing methods of the SEM results, the percentage of $\mathrm{C}-\mathrm{S}-\mathrm{H}$ within the samples are very similar for each testing day. For instance, the when looking into the 56 day results, the control water and vacuum samples show approximately 70 percent of C-S-H formation. Similarly, when comparing the 56 day results for the 3 and $5 \%$ of nano silica replacement samples, notice the same percentage of C-S-H formation of 83 and $85 \%$, respectively. From these results, the curing methods performed identical in the curing of the samples and formation of C-S-H. In 
consequence, the vacuum curing method deems suitable as another reliable form of concrete curing.

\section{Fourier Transform Infrared Spectroscopy (FTIR)}

The FTIR was used to monitor the hydration process of Portland cement with and without the addition of nano silica between 3 to 56 days. From the results, the areas of possible C-S-H formation have been determined for all samples tested. FTIR results show that with the incorporation of nano silica, the areas C-S-H in the region varies in comparison to the control samples. In the control samples, the area in which the C-S-H formation increases as the samples cured up to 56 days. With the addition of nano silica replacement, the areas of C-S-H show significant increase in the water and vacuum cured samples.

\section{Conclusion}

In this study, the hydration process of Portland cement with additives of nano silica has been monitored. With the use of SEM and FTIR, signatures of C-S-H which produce most of the concretes' strength, has been determined and examined with age. Also, using Forney and MTS testing equipment, the overall strength of the harden cement pastes were determined and recorded for analysis. The objective of this report was to demonstrate how FTIR and SEM can give more insight on the hydration of cement, with and without the incorporation of nano silica, during the later ages or stages of hydration. From this study and results obtained, several conclusions have been drawn:

- The area of possible formation of C-S-H was determined to show an increase with respect to time; signifying the increase in strength with age

- In comparing water and vacuum curing methods, the vacuum cured samples perform identically to that of the water cured when monitoring the hydration. Results indicate similar increases with age between both methods

- Nano silica in all percentages of cement replacements showed a significant increase in compressive strength in all ages of testing. When comparing the amount of nano silica replacement, results show the optimal percentage of cement replacement is that of the $1 \%$, followed close by the $3 \%$ nano silica addition. $5 \%$ nano silica replacement results portrayed a decrease in strength in comparison to that of the 1 and $3 \%$ additions

- Water curing proved to be the beneficial form of curing by displaying higher overall strength values than that of the vacuum cured method. Yet, the compressive strength of vacuum cured specimens showed a small reduction in compressive strength (usually within 5\%), when compared to the water cured samples

\section{Acknowledgment}

This paper summarizes the findings of a research work supported in part by the National Science Foundation (NSF). Any findings, conclusions and recommendations expressed in this paper are those of the authors.

\section{Funding Information}

The work reported here was financially supported by the National Science Foundation (NSF).

\section{Author's Contributions}

Justin Montgomery: Participated in all experimental testing, data-analysis and contributed to the writing of the manuscript.

Taher M. Abu-Lebdeh: Participated in experimental plan and testing, data-analysis and contributed to the writing of the manuscript

Sameer A. Hamoush: Participated in experimental plan, data-analysis and contributed to the writing of the manuscript

Miguel Picornell: Participated in experimental plan, data-analysis and contributed to the writing of the manuscript.

\section{Ethics}

The authors would like to disclose that Dr. Taher M. Abu-Lebdeh (Co-author) is a member of the editorial board for the American Journal of Engineering and Applied Sciences.

\section{References}

Belkowitz, J. and D. Armentrout, 2009. The investigation of nano silica in the cement hydration process. ACI Special Publication.

Bi, J., I. Pane, B. Hariandja and I. Imran, 2012. The use of nanosilica for improving of concrete compressive strength and durability. Applied Mechan. Mater., 204: 4059-4062.

DOI: 10.4028/www.scientific.net/AMM.204-208.4059

Elkady, H., M. Serag and M. Elfeky, 2013. Effect of nano silica de-agglomeration and methods of adding superplasticizer on the compressive strength and workability of nano silica concrete. Civil Environ. Res., 3: 21-34.

Givi, A.N., S.A. Rashid, F.N.A. Aziz and M.A.M. Salleh, 2010. Experimental investigation of the size effects of $\mathrm{SiO}_{2}$ nano-particles on the mechanical properties of binary blended concrete. Composites Part B: Eng., 41: 673-677.

DOI: $10.1016 /$ j.compositesb.2010.08.003 
Gopinath, S., P.C. Mouli, A. Murthy, N. Iyer and S. Maheswaran, 2012. Effect of nano silica on mechanical properties and durability of normal strength concrete. Archives Civil Eng., 58: 433-444. DOI: $10.2478 / \mathrm{v} .10169-012-0023-y$

Lin, F. and C. Meyer, 2009. Hydration kinetics modeling of Portland cement considering the effects of curing temperature and applied pressure. Cement Concrete Res., 39: 255-265.

DOI: 10.1016/j.cemconres.2009.01.014

Quercia, G., P. Spiesz, G. Husken and J. Brouwers, 2012 Effects of Amorphous Nano-Silica Additions on Mechanical and Durability Performance of SCC Mixtures. Proceedings of the International Congress on Durability of Concrete, (CDC' 12).

Salkhordeh, S., P. Golbazi and H. Amini, 2011. The improvement of 28-day compressive strength of SCC made by different percentages of recycled concrete aggregates using nano-silica.
TrapoteBarreira, A., 2015. Dissolution kinetics of CSH Gel and durability of mortar. Materials, 19: 01-01.

Winter, N.B., 2012. Understanding Cement: The Fast Star User-friendly Insight into Cement Production, Cement Hydration and Cement and Concrete Chemistry. 1st Edn., WHD Microanalysis Consultants Ltd., ISBN-10: 0957104529, pp: 206

Zaki, S.I. and K.S. Ragab, 2009. How nanotechnology can change concrete industry. Proceedings of the International Conference Sustainable Built Environment Infrastructures in Developing, (EID' 09), pp: 407-414. 